\title{
Characterization and mechanical properties investigation of the cellulose/gypsum composite
}

Journal of Composite Materials 2016, Vol. 50(5) 657-672 (C) The Author(s) 2015 Reprints and permissions: sagepub.co.uk/journalsPermissions.nav DOI: 10.1 |77/002|9983।5580826 jcm.sagepub.com

SAGE

\author{
Fitriana Nindiyasari', Erika Griesshaber', Tanja Zimmermann², \\ Avinash Pradip Manian ${ }^{3}$, Clemens Randow ${ }^{4}$, Rolf Zehbe ${ }^{4}$, \\ Lurdes Fernandez-Diaz ${ }^{5,6}$, Andreas Ziegler ${ }^{7}$, Claudia Fleck ${ }^{4}$ and \\ Wolfgang W Schmahl'
}

\begin{abstract}
We synthesized cellulose/gypsum composites in the presence and absence of sodium alginate and investigated the interaction between the composite components as well as the mechanical properties of the final composites. Four different types of cellulose fiber materials were used: cellulose UFCI00, cellulose B400, nanofibrillated cellulose, and Lyocell fiber. For all investigated composites the total amount of admixed cellulose was between I and 2 wt\%, the amount of admixed sodium alginate was $0.5 \mathrm{wt} \%$. We determined the morphology of the composites and observed that the particle and fiber dimensions of the admixed cellulose affect the mode of gypsum-gypsum interlocking and the total porosity of the composites. This in turn had a substantial influence on the mechanical properties of the final composite materials. The addition of sodium alginate resulted in an increase of ultimate strain values. Composites with Lyocell fiber, a synthetic fiber, also had a high Young's modulus.
\end{abstract}

\section{Keywords}

Gypsum, hemihydrate, sodium alginate, cellulose fiber, mechanical properties, porosity

\section{Introduction}

Gypsum is a well-known low-cost material. ${ }^{1}$ It is composed of interconnected needle-like calcium sulphate dihydrate crystals. These cystals entangle and create a gypsum network. The main drawback of gypsum as a building material is due to its heaviness and brittleness. This drawback can be overcome by combining gypsum with mineral particles, ${ }^{2}$ natural fibers (waste paper, ${ }^{3}$ sisal fiber, ${ }^{4}$ stalk fiber, ${ }^{5}$ hemp fiber $^{6}$ ), synthetic fibers (polyamide fiber, ${ }^{7,8}$ glass fiber $^{9-11}$ ), or polymers. ${ }^{12}$ Gypsum-based composites have a low cost production, a low thermal coefficient ${ }^{5}$ and a low solid content. All these properties are good for insulating against heat and sound while the mechanical strength of the gypsum-based composites are still retained. ${ }^{5,13}$

The mechanical properties of gypsum are correlated to its total porosity. ${ }^{7,12-16}$ It turns out that the total porosity of gypsum is influenced by the water/hemihydrate ratio $^{4,13-16}$ and the aging time. ${ }^{4,14-19}$ It is well known that the total porosity increases when the water/hemihydrate ratio increases. ${ }^{14-16}$ Moreover, the network structure, the intercrystalline interaction, the crystal sizes, and

\footnotetext{
'Department für Geo- und Umweltwissenschaften, Ludwig-MaximiliansUniversität München, Germany

${ }^{2}$ Department of Applied Wood Materials, Swiss Federal Laboratories for Materials Science and Technology (EMPA), Switzerland

${ }^{3}$ Laboratory for Textile and Fiber Chemistry in Cellulosics, Research Institute for Textil Chemistry and Textile Physics, University of Insbruck, Austria

${ }^{4}$ Department of Material Engineering, Technische Universität Berlin, Germany

${ }^{5}$ Department of Crystallography and Mineralogy, Universidad Complutense, Spain

${ }^{6}$ Institut of Geoscience, IGEO (CSIC, UCM), Spain

${ }^{7}$ Central Facility for Electron Microscopy, University of Ulm, Germany
}

\section{Corresponding author:}

Fitriana Nindiyasari, Department für Geo- und Umweltwissenschaften, Ludwig-Maximilians-Universität, 80333 Munich, Germany.

Email: f.nindiyasari@Imu.de 
the pores affect the mechanical properties of the gypsum. ${ }^{13,16}$ The crystalline habits and the arrangement of the crystals influence the hardness of the gypsum, as explained by Amathieu (1986). ${ }^{20}$ The hardness of the gypsum increases by a factor of two to three with reducing the crystal size from micrometer to nanometer scale level. This increase is attributed to the strong entanglement of the gypsum needle-like network. ${ }^{21}$

Cellulose is embedded into gypsum wallboard. Gypsum wallboard is an important construction material for building for example an interior wall. ${ }^{22,23}$ The main drawback of wallboard is failure that occurs at the cellulose-gypsum interface. ${ }^{23}$ Cellulose is formed by sequences of glucose repeating units and has good mechanical properties such as high tensile strength and Young's modulus. ${ }^{24-26}$ There are six different cellulose polymorphs, cellulose I, II, III $, \mathrm{III}_{\mathrm{II}}, \mathrm{IV}_{\mathrm{I}}$, and $\mathrm{IV}_{\text {II. }}{ }^{27-31}$

This paper focuses on the effect of natural (cellulose Arbocel UFC100, B400, and NFC) and synthetic (Lyocell fiber) cellulose in the formation of gypsum crystals and entanglement of the gypsum-gypsum networks. De Maria Pinheiro Correia (2009) reported an increase in mechanical properties and a thermal conductivity of low porosity gypsum plates by an addition of nanofibril cellulose. ${ }^{32}$ The addition of sodium alginate is expected to reduce the cellulose-gypsum interface failure by creating an intimate interlinkage of the components. ${ }^{33}$

\section{Materials and material preparation}

\section{Materials}

Chemical compounds such as sodium alginate and hemihydrate $\left(\mathrm{CaSO}_{4} \cdot 1 / 2 \mathrm{H}_{2} \mathrm{O}\right)$ were obtained from Sigma Aldrich $\mathrm{GmbH}$, Germany, while cellulose Arbocel was obtained from JRS Pharma GmbH \& Co. KG, Germany. Lyocell fiber was obtained from Tencel ${ }^{\circledR}$ Lenzing AG, Lenzing, Austria.

Cellulose. Cellulose I or native cellulose is a polymorph that is found in nature. Cellulose I has two different polymorphs: cellulose I $\alpha$ and I $\beta$. Cellulose I $\alpha$ and cellulose I $\beta$ have the same conformation of the heavy atom skeleton but differ in hydrogen bonding patterns. Cellulose $I \alpha$ is a metastable phase with a triclinic unit cell containing one chain, while cellulose I $\beta$ has two chains in its monoclinic unit cell. Cellulose II, derived from cellulose I, has a similar unit cell as the unit cell of cellulose I. The main difference to cellulose I is that cellulose II has two cellulose chains that lie antiparallel to one another. ${ }^{29,31}$

Swelling agents such as water or alkali treatments ( $\mathrm{NaOH}$ up to $8 \mathrm{M}$ ) influence the degree of swelling, the degree of crystallinity and the water retention value (WRV) of the cellulose fiber, respectively. Water retention value is an ability of cellulose to uptake water. ${ }^{34-37}$ In water or under alkali treatment of 2-4 M NaOH cellulose II can swell extensively in comparison to cellulose $\mathrm{I}^{36,37}$ On the other hand under strong alkali treatment, e.g. 5-8 $\mathrm{M} \mathrm{NaOH}$, cellulose I will swell more extensively than cellulose II.

As shown in Table 1, four different cellulose fibers were taken for the preparation of the composites: 1 . Arbocel UFC100 an ultrafine cellulose powder with a particle size of $1 \mu \mathrm{m} ; 2$. Arbocel B400 a fibrous cellulose with fiber lengths of about $900 \mu \mathrm{m}$ and a fiber diameter of about $10 \mu \mathrm{m} ; 3$. Lyocell fiber with a fiber length of $38 \mathrm{~mm}$ and a fiber fineness of $1.3 \mathrm{dtex}$. Dtex is the mass of fiber in grams per $10000 \mathrm{~m}$ length. The higher the dtex value the thicker or coarser is the fiber. ${ }^{34,36} 4$. Nanofibrillated cellulose (NFC) with fiber lengths of $2 \mu \mathrm{m}$ and a fiber diameter in the range of several ten nanometers.

Nanofibrillated cellulose production. Nanofibrillated cellulose (NFC) was prepared by dispersing $0.93 \mathrm{~kg}$ of Arbocel B1011 cellulose fiber in $9 \mathrm{~L}$ of water. First, the suspension was left in a thermo-static reactor at $10^{\circ} \mathrm{C}$ under continuous stirring for 4 days. Subsequently, the cellulose suspension was processed through a closed inline dispersing system equipped with an ultra-turrax for the disintegration of the fibers into smaller parts. The resulting suspension was treated in a high pressure homogenizer by pumping the resulting suspension with high velocities through fixedgeometry interaction chambers ( $\mathrm{Y}$ or $\mathrm{Z}$ morphology) with diameters of 400,200 , and $75 \mu \mathrm{m}$. Pressures up to 1000 bar were applied to generate high shear stresses to the cellulose fibers. ${ }^{38}$ The NFC is prepared as a suspension to preserve the NFC structure with content of $1.5 \mathrm{wt} \%$ NFC ( $1.5 \mathrm{~g} \mathrm{NFC}$ in $100 \mathrm{~mL}$ water). The centrifugation and the heat appliance to reduce the water content yielded to the NFC content of $2 \mathrm{wt} \%$ $(2 \mathrm{~g} \mathrm{NFC}$ in $100 \mathrm{~mL}$ water). Further heat appliance may lead to structure destruction of the NFC and centrifugation does not resolve to more water content reduction. This results to a problem in $w_{\mathrm{o}} / h_{\mathrm{o}}$ ratio adjustment of the cellulose/gypsum composites. NFC, reported by some authors, has interesting properties such as high strength and high stiffness. ${ }^{39-42}$

Sodium alginate. Alginate is a natural polymer and is derived from cell walls of brown algae. ${ }^{43}$ Alginate can be found as sodium alginate, calcium alginate, and magnesium alginate salts within the cell walls and intercellular mucilage of seaweed. ${ }^{44}$ It is a hydrophylic gelling material that has interesting properties such as stabilizing emulsions, high capacity of holding water 
Table I. Bending and compressive strength values of gypsum composites that are completed with the water/hemihydrate ratio $\left(w_{\circ} / h_{\circ}\right)$, cellulose content (wt\%), and sodium alginate content $(w t \%)$.

\begin{tabular}{|c|c|c|c|c|c|}
\hline & $w_{o} / h_{o}$ ratio & $\begin{array}{l}\text { Cellulose } \\
\text { content (wt\%) }\end{array}$ & $\begin{array}{l}\text { Sodium alginate } \\
\text { content (wt\%) }\end{array}$ & $\begin{array}{l}\text { Compressive } \\
\text { strength }(\mathrm{MPa})\end{array}$ & $\begin{array}{l}\text { Bending } \\
\text { strength }(\mathrm{MPa})\end{array}$ \\
\hline Gypsum & 0.50 & - & - & $9.25 \pm 1.25$ & $5.65 \pm 1.15$ \\
\hline Sodium alginate & 0.50 & - & 0.5 & $6.04 \pm 1.29$ & $3.00 \pm 0.58$ \\
\hline Composite UFC Ia & 0.50 & 1.0 & - & $17.82 \pm 1.07$ & $6.16 \pm 0.94$ \\
\hline Composite UFC Ib & 0.50 & 1.0 & 0.5 & $9.02 \pm 0.93$ & $4.67 \pm 0.74$ \\
\hline Composite UFC IC & 0.50 & 2.0 & - & $5.98 \pm 0.89$ & $3.55 \pm 1.09$ \\
\hline Composite UFC Id & 0.50 & 2.0 & 0.5 & $10.5 \mid \pm 0.96$ & $4.45 \pm 0.71$ \\
\hline Composite B400 2a & 0.50 & 1.0 & - & $10.34 \pm 0.44$ & $4.49 \pm 1.11$ \\
\hline Composite B400 2b & 0.50 & 1.0 & 0.5 & $7.76 \pm 0.59$ & $4.42 \pm 0.38$ \\
\hline Composite B400 2c & 0.50 & 2.0 & - & $6.38 \pm 0.72$ & $2.78 \pm 0.67$ \\
\hline Composite B400 2d & 0.50 & 2.0 & 0.5 & $6.62 \pm 0.28$ & $3.72 \pm 0.23$ \\
\hline Composite Lyo 3a & 0.50 & 1.0 & - & $10.52 \pm 0.79$ & $5.40 \pm 1.19$ \\
\hline Composite Lyo 3b & 0.50 & 1.0 & 0.5 & $7.94 \pm 1.26$ & $3.66 \pm 0.47$ \\
\hline Composite Lyo 3c & 0.50 & 2.0 & - & $6.09 \pm 0.69$ & $4.00 \pm 0.47$ \\
\hline Composite Lyo 3d & 0.50 & 2.0 & 0.5 & $5.71 \pm 0.18$ & $4.04 \pm 0.80$ \\
\hline Composite NFC 4a & 0.50 & 1.0 & - & $10.95 \pm 0.91$ & $4.21 \pm 0.70$ \\
\hline Composite NFC 4b & 0.50 & 1.0 & 0.5 & $10.1 I \pm 0.76$ & $3.31 \pm 0.83$ \\
\hline Composite NFC 4c & 0.97 & 2.0 & - & $3.17 \pm 0.14$ & $\mathrm{I} .35 \pm 0.34$ \\
\hline Composite NFC 4d & 0.97 & 2.0 & 0.5 & $4.21 \pm 0.22$ & $\mathrm{I} .72 \pm 0.36$ \\
\hline
\end{tabular}

and improved viscosity. ${ }^{43}$ Sodium alginate contributes to the mechanical strength and the flexibility of algae and is comparable to the cellulose of land plants. ${ }^{45}$

Sodium alginate is used in wide-range applications. Recently, some researchers investigated the application of sodium alginate in building and construction materials such as in cements, ${ }^{46}$ clays, ${ }^{43}$ and soils. ${ }^{47}$ An increase in compressive strength from 2.23 to 3.77 MPa by adding up to $19 \mathrm{wt} \%$ of sodium alginate to clay is reported by Marín-Galán et al. (2010). ${ }^{43}$

\section{Production of gypsum-cellulose composites}

Several different composites were prepared from the four different cellulose types described above. The water/hemihydrate ratio $\left(w_{\mathrm{o}} / h_{\mathrm{o}}\right)$, the cellulose and the sodium alginate contents were adjusted to get the chosen value (Table 1). $1 \mathrm{M} \mathrm{NaOH}$ was added in order to produce well dispersed sodium alginate. This amount is well below the swelling maximum of cellulose fiber and does not influence the swelling degree of cellulose.

\section{Methods}

\section{Microscope imaging}

For scanning electron microscopy (SEM), dried cellulose UFC100, B400, the Lyocell fiber and sodium alginate samples were mounted on the holder using carbon tape. They were then coated with carbon and gold. The morphology of the samples was imaged with a JEOL JSM-6500F SEM using an accelerating voltage of $10 \mathrm{kV}$. A drop of the nanofibrillated cellulose (NFC) was placed on a TEM grid and the NFC was imaged with a Zeiss EM 10 TEM using an accelerating voltage of $80 \mathrm{kV}$.

\section{X-ray diffraction}

The fine crystalline cellulose UFC100 and the thin film of NFC, were investigated using a Bragg-Brentano X-ray diffractometer (GE: XRD 3003 TT). X-ray diffraction (XRD) data were recorded in reflection mode using a 1-dimensional position sensitive semi conductor detector (Meteor 1D) with a step size of $0.01^{\circ}(\theta / \theta)$. The thin film of nanofibrillated cellulose (NFC) was obtained by drying some amount of NFC inside an oven at a temperature of $60^{\circ} \mathrm{C}$ for $24 \mathrm{~h}$. This diffractometer was also used to record diffraction patterns of hemihydrate, gypsum and the composite UFC 1a, in order to follow the transformation of hemihydrate to gypsum.

Both samples, the cellulose B400 and Lyocell fiber, were packed into glass capillaries $(\varnothing=0.5 \mathrm{~mm})$. XRD data was collected in transmission mode on a single crystal diffractometer (Agilent, Gemini Ultra) equipped with a two-dimensional charge-coupled 


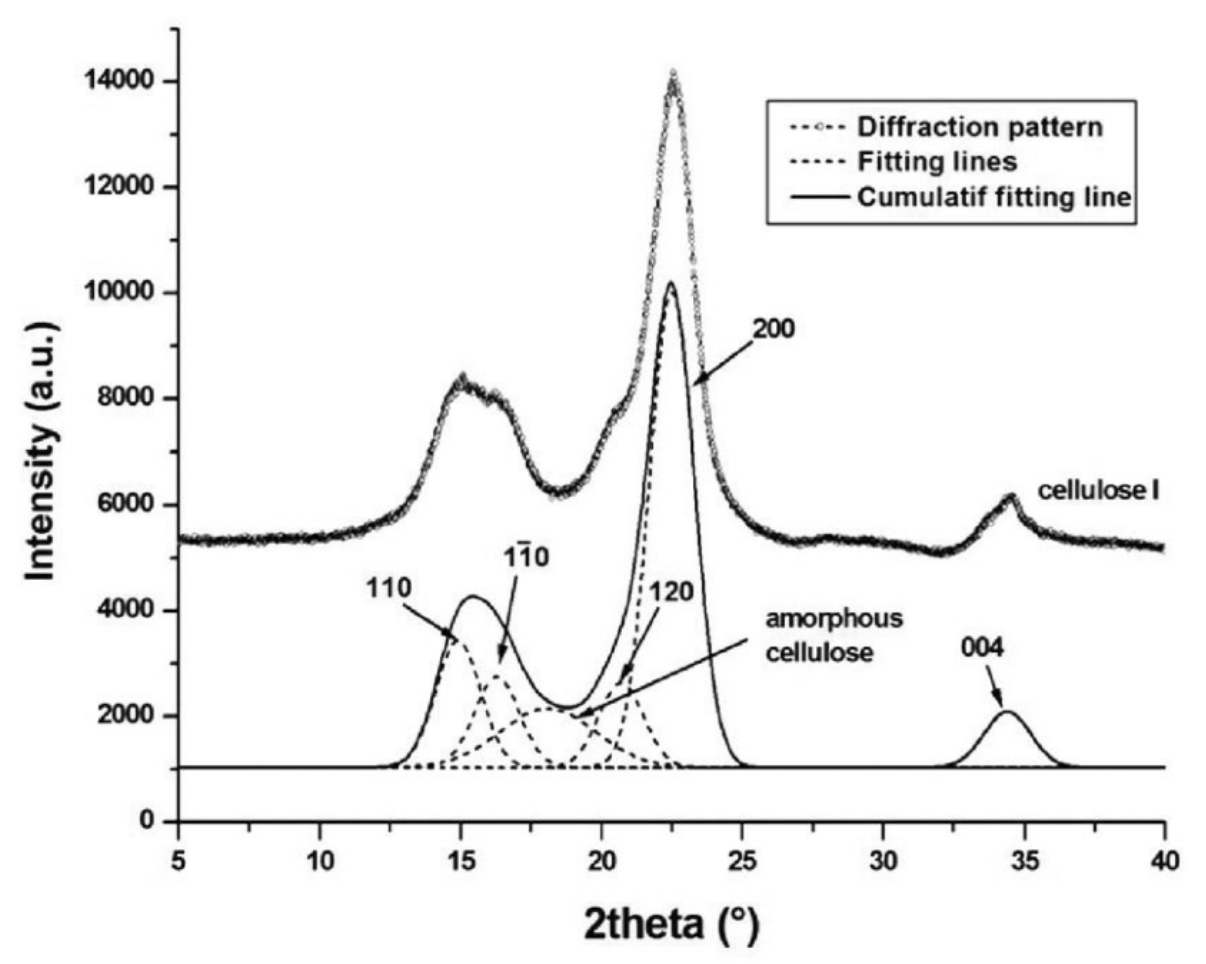

Figure I. Diffraction pattern of cellulose I showing peak deconvolution. The diffraction pattern has five major reflections at II0, ITO, 120, 200, and 004 for the crystalline phase. Amorphous phase of cellulose I is observed at $2 \theta \sim 18^{\circ}$.

detector (Atlas). All XRD data were collected using $\mathrm{Cu}$ $\mathrm{K} \alpha_{1}$ radiation.

The degree of crystallinity and the apparent crystallite size were estimated by deconvolution of the diffraction patterns in the range of $10-40^{\circ}(2 \theta)$ (Figure 1). The Gaussian profile function was applied for the deconvolution of the intensity of the four reflections $110,1 \overline{1} 0$, 120 , and 200, respectively, for crystalline cellulose $27,30,35$ and one broad peak at $2 \theta \sim 18^{\circ}$ for amorphous cellulose. ${ }^{36,37}$ The crystallinity index was calculated according to $X_{c}=\left[A_{c r} /\left(A_{c r}+A_{a m}\right)\right] \times 100 \%$, where $A_{c r}$ and $A_{a m}$ are the integrated intensities of the crystalline and amorphous phases, respectively. ${ }^{38-40}$ The apparent crystallite size $(L)$ was calculated according to the Scherrer equation $L=k \lambda /(\beta \cos \theta)$, where the Scherrer constant $k$ for an unknown crystal phase has been set to 0.9. $\lambda$ stands for the applied X-ray wavelength, $\beta$ is the FWHM of the reflections 200 for cellulose I and 020 for cellulose II in radian, and $\theta$ is the corresponding Bragg's angle. ${ }^{48-52}$

\section{Porosity measurement}

The total porosity of the composites was calculated from the water-to-stucco ratio, $p=\left(w-\left(w_{o} / h_{o}\right.\right.$ ratio $\left.)\right) /$ ( $w+$ weight of cellulose) where $w$ is the total weight of the gypsum composite. It follows the Gibson-Ashby relation where the strength of the composite scales with (1-porosity). ${ }^{13}$

\section{Mechanical testing}

For mechanical testing, the samples were prepared by pouring the composite slurry into moulds with dimensions of $13.5 \times 13.5 \times 25 \mathrm{~mm}^{3}$ for compression and $75 \times 10 \times 3.5 \mathrm{~mm}^{3}$ for four-point bending testing. The samples were dried within the moulds at room temperature for 7 days. The number of specimens for each composite was $\sim 10$ specimens for bending and $\sim 10$ specimens for compression testing. Bending testing was carried out with a UTS test system Typ 009, $3 \mathrm{kN}$ and with a Zwick Universalprüfmaschine Typ Z005, $5 \mathrm{kN}$ while compression testing was carried out with a Zwick Universalprüfmaschine Typ 1425, $100 \mathrm{kN}$ and a Zwick Universalprüfmaschine Typ Z005, $5 \mathrm{kN}$. Measurement was stopped after the load dropped and the first cracks were observed. Some specimens failed at point of force transmission due to uneven surfaces and were excluded from data interpretation. The preload for bending and compression testing was $0.5 \mathrm{~N}$. The velocity values of bending and compression testing were $0.02 \mathrm{~mm} / \mathrm{min}$ and $0.12 \mathrm{~mm} / \mathrm{min}$, respectively. The strain rate values of bending and compression testing were $5.1 \times 10^{-5} \mathrm{~s}^{-1}$ and $8 \times 10^{-5} \mathrm{~s}^{-1}$, respectively. The strain is calculated by dividing the elongation by the original sample length. The Young's moduli are derived from the steep slope of stress-strain curve. The bending strength calculation is based on four-point bending experiments. Thus, $\sigma=\frac{3 F d}{b h^{2}}$, where $F$ is the applied load, $d$ is the distance between the 

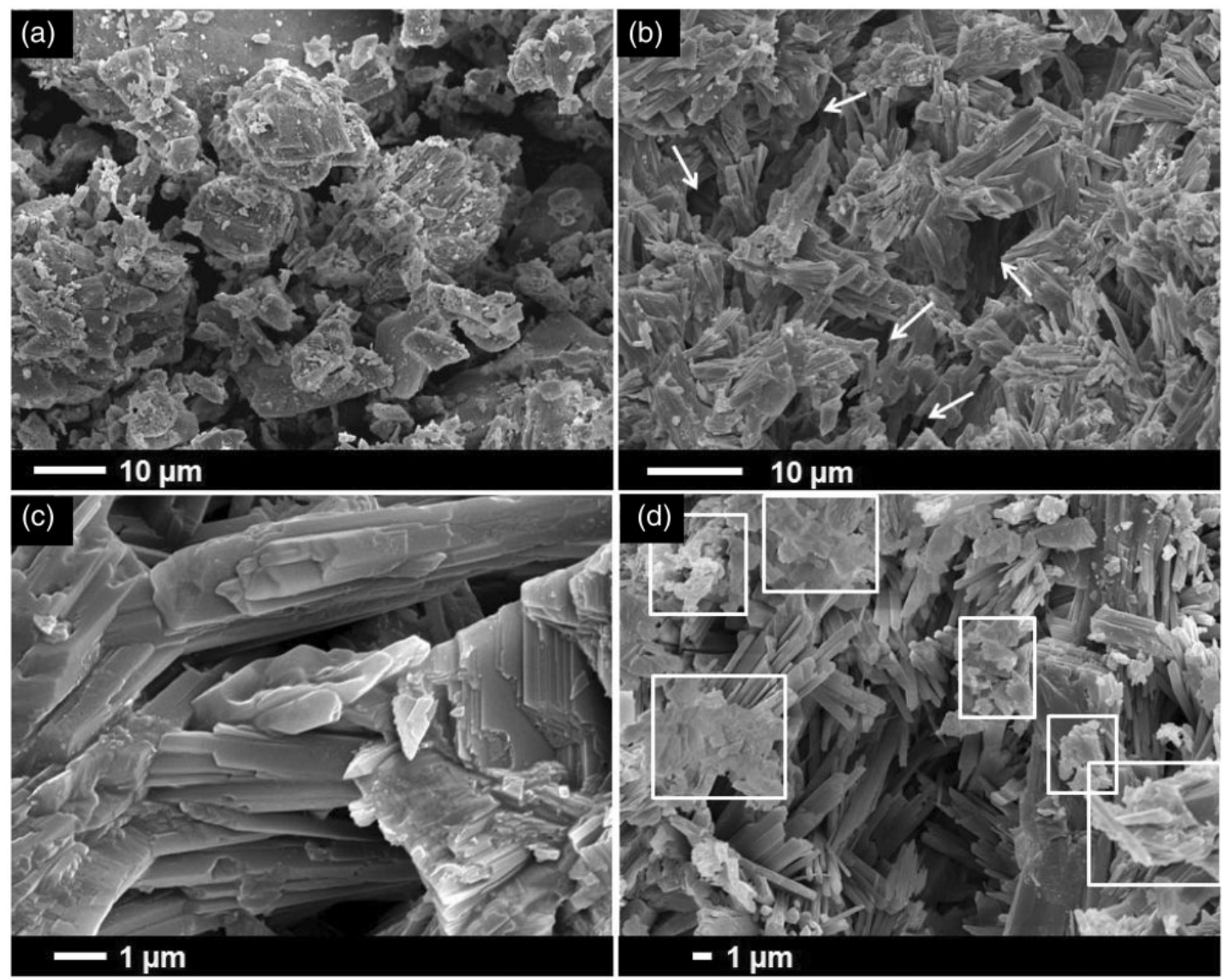

Figure 2. SEM images of (a) $\beta$-hemihydrate $\left(\mathrm{CaSO}_{4} \cdot \mathrm{I} / 2 \mathrm{H}_{2} \mathrm{O}\right)$ showing the irregular shape of $\beta$-hemihydrate aggregates and (b) fracture surface of gypsum (hydrated $\beta$-hemihydrate) with a water/hemihydrate $\left(w_{\circ} / h_{\circ}\right)$ ratio of 0.5 . Hydrated $\beta$-hemihydrate highlighted in (c) displays the mode of interlocking of gypsum-gypsum crystals. Interlocking of gypsum-gypsum crystals creates porous gypsum aggregates indicated by white arrows in (b) while white squares in (d) indicate chunks of hemihydrate that remain intake.

inner and the outer points of the bending machine, $b$ is the sample width $(10 \mathrm{~mm})$, and $h$ is the sample thickness $(35 \mathrm{~mm})$. The compressive strength is calculated by dividing the applied load by the surface area of the samples.

\section{Results}

\section{Gypsum crystallization (formation)}

Gypsum crystallization occurs as a result of a solvent mediated transformation that involves dissolution of hemihydrate as well as nucleation and growth of gypsum. ${ }^{53}$ The driving force for this process is the different solubility of gypsum and hemihydrates, i.e. gypsum is less soluble in water than hemihydrate. As a consequence, in contact with water, the dissolution of hemihydrate leads to supersaturation of gypsum in the solution. At this point, gypsum can nucleate and, for the solute consumption involved, the system becomes again undersaturated with respect to hemihydrates. The coupling between hemihydrate dissolution and gypsum crystallization defines a feedback loop which guarantees that gypsum growth occurs under a constant supersaturation value that is controlled by the solubility difference between gypsum and hemihydrate. This mechanism will operate while both water and hemihydrates remain available in the system.

Figure 2 shows $\mathrm{SEM}$ images of hemihydrate $\left(\mathrm{CaSO}_{4} \cdot 1 /\right.$ $\left.2 \mathrm{H}_{2} \mathrm{O}\right)$ and gypsum $\left(\mathrm{CaSO}_{4} \cdot 2 \mathrm{H}_{2} \mathrm{O}\right)$. Hemihydrate crystals have an irregular shape and are aggregates of small crystallites (Figure 2(a)). The single crystal size of $\beta$-hemihydrate is in the range of $1-10 \mu \mathrm{m}$. The entanglement of gypsum needle-like network (Figure 2(c)) creates pores with pore sizes in the range of 5-10 $\mu \mathrm{m}$ ((Figure 2(b)). As shown in Figure 2(d), small particles of $\beta$-hemihydrate appear indicating that some $\beta$-hemihydrate does not recrystallize to gypsum. This occurs due to an insufficient amount of water and/or a too short hydration time.

\section{Cellulose particle, fiber morphology, and crystallinity characterization}

Diffraction patterns of the cellulose UFC100, B400, and NFC (Figure 3) resolve the presence of the 


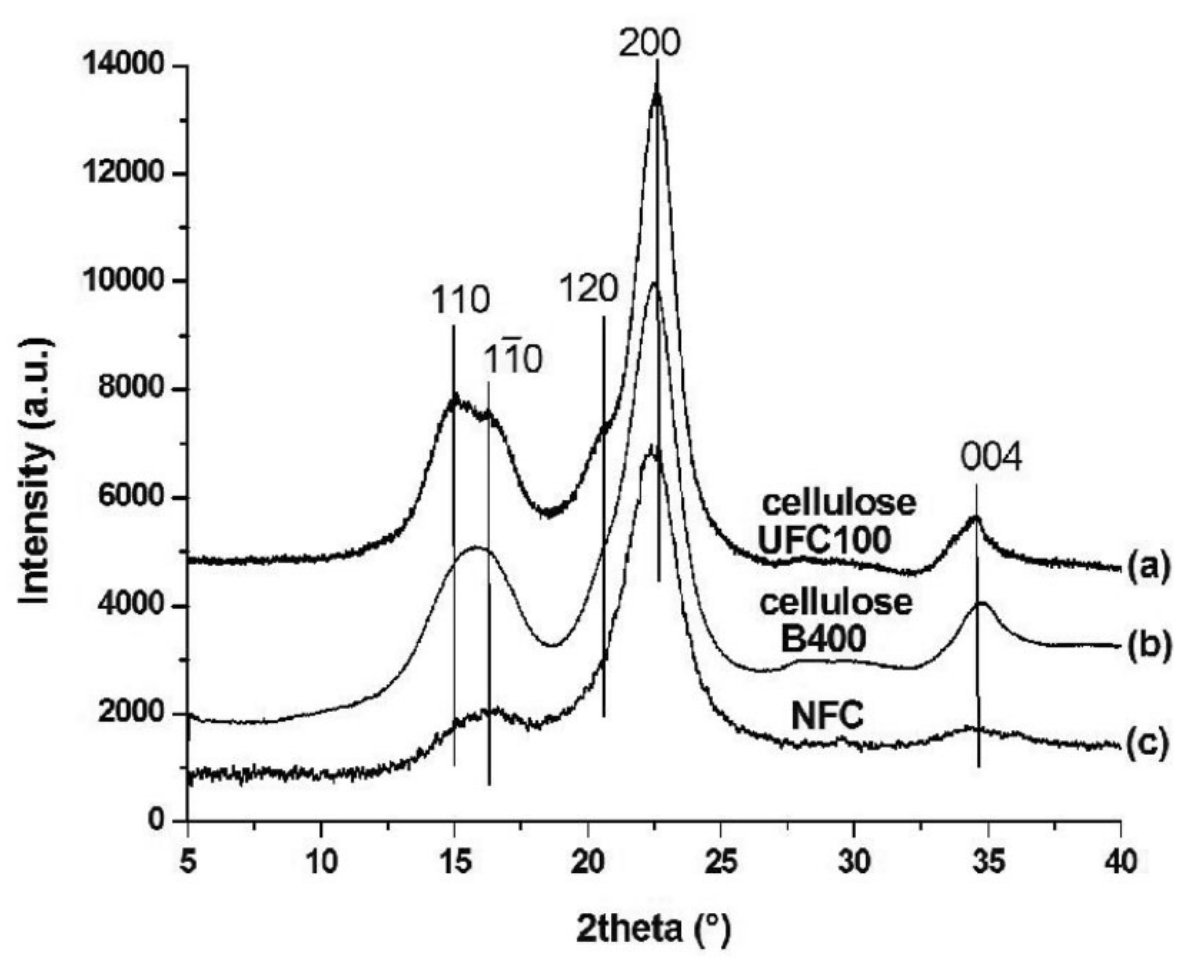

Figure 3. Diffraction patterns of the cellulose (a) UFCI00, (b) B400, and (c) NFC show characteristic reflections of cellulose polymorph I. There are several overlapping peaks appear at $2 \theta \sim 15^{\circ}$ and $2 \theta \sim 22^{\circ}$.

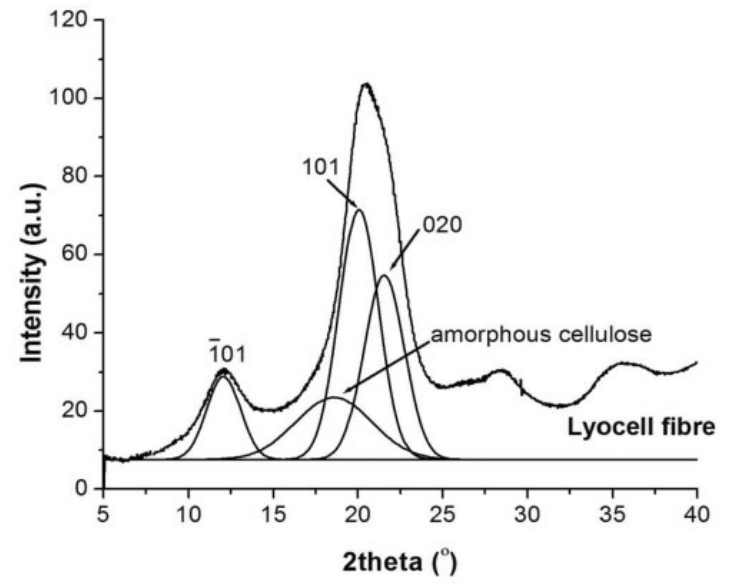

Figure 4. Diffraction pattern of Lyocell fiber and the deconvolution of the intensity of reflections TOI, I0I, and 020 of cellulose polymorph II along with a broad peak of an amorphous phase at $2 \theta \sim 18^{\circ}$.

cellulose polymorph I. Cellulose polymorph I has the following five major reflections: 110 at $2 \theta \sim 15.12^{\circ}, 1 \overline{1} 0$ at $2 \theta \sim 16.35^{\circ}, 120$ at $2 \theta \sim 20.57^{\circ}, 200$ at $2 \theta \sim 22.50^{\circ}$, and 004 at $2 \theta \sim 34.57^{\circ}$. The diffraction patterns of cellulose II or Lyocell fibers reveals three peaks $\overline{1} 01,101$, 020 with reflections at $12.4^{\circ}, 20.6^{\circ}$, and $21.4^{\circ}(2 \theta)$, respectively (Figure 4).
Table 2. The apparent crystallite size ( $L$ ) and the degree of crystallinity evaluated from the intensity of the crystalline phase reflections using the Scherrer equation.

\begin{tabular}{lll}
\hline & $\begin{array}{l}\text { Apparent } \\
\text { Crystallite } \\
\text { size } L(\mathrm{~nm})\end{array}$ & $\begin{array}{l}\text { Degree of } \\
\text { crystallinity } \\
\mathrm{X}_{\mathrm{c}}(\%)\end{array}$ \\
\hline Cellulose UFCI00 & 4.28 & 75.5 \\
Cellulose B400 & 3.64 & 70.2 \\
Lyocell & 3.47 & 52.3 \\
NFC & 3.56 & 67.8 \\
\hline
\end{tabular}

The degree of crystallinity and apparent crystallite size calculations of cellulose UFC100, B400, Lyocell fiber as well as NFC cellulose are given in Table 2. The apparent crystallite sizes evaluated from XRD data are based on the line broadening of the reflection 200 for cellulose I and 020 for cellulose II. These reflections are related to the thickness of the molecular sheets in the stacking direction of the a-axis of the cellulose unit cell. A reduction of the crystallite size can be assumed by a change in cellulose chains along the plane (200) or (020), resulting in an apparent crystallite size of $4.28,3.64$, and $3.56 \mathrm{~nm}$ for UFC100, B400 and NFC, respectively. Cellulose UFC100 has a degree of crystallinity of $75.5 \%$, while cellulose B400 and NFC show a degree of crystallinity of $70.2 \%$ and 

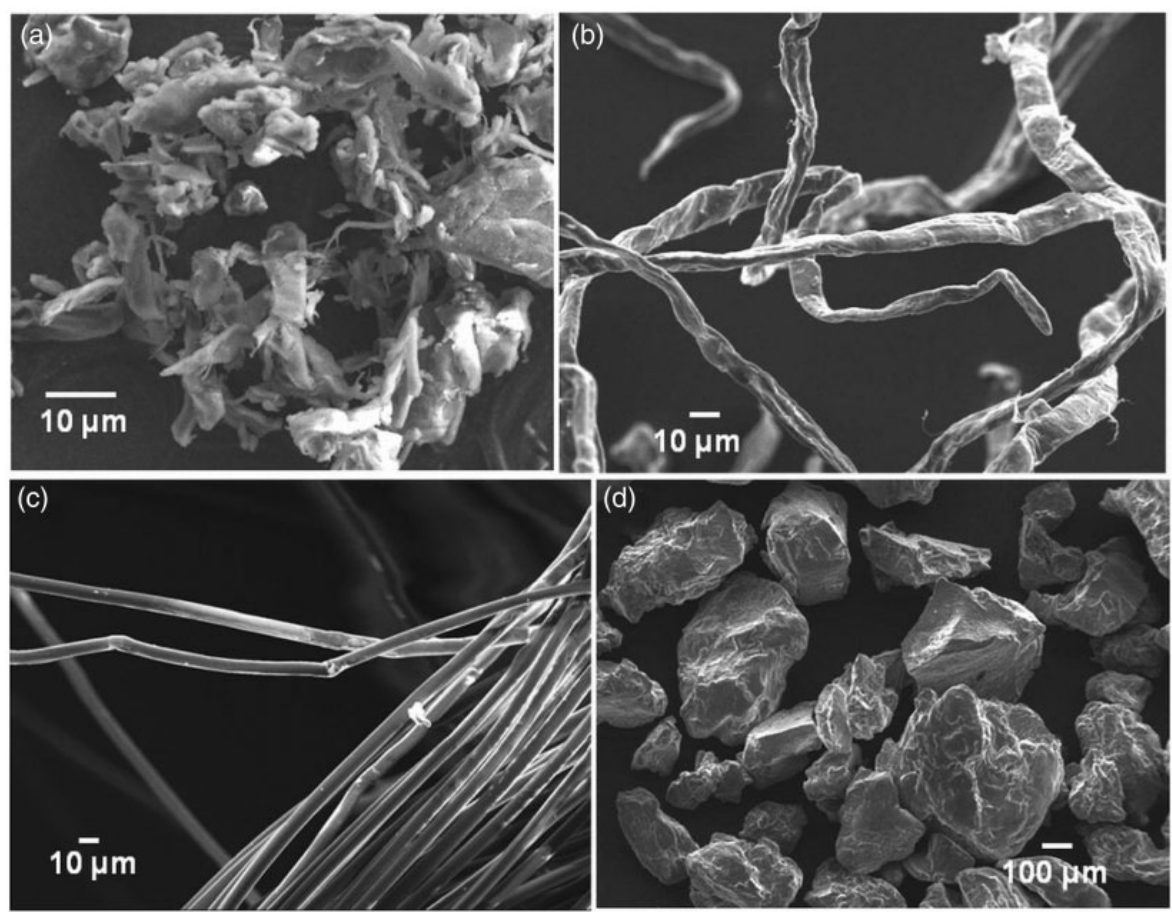

Figure 5. SEM images of the morphology of (a) cellulose UFCI00, (b) cellulose B400, (c) Lyocell fiber and (d) sodium alginate. Cellulose UFCI00 appears as aggregate of small cellulose particles while both cellulose B400 and Lyocell fiber are fibrous cellulose with diameter about $10 \mu \mathrm{m}$.

$67.8 \%$, respectively. Lyocell fiber has the lowest crystallinity index and apparent crystallite among the other cellulose with a respective value of $52.3 \%$ and $3.47 \mathrm{~nm}$.

Figure 5 shows the morphology of cellulose UFC100, cellulose B400, Lyocell fiber, and sodium alginate. Cellulose UFC100 is an aggregate of irregular particles, while cellulose B400 and Lyocell fiber are entirely composed of cellulose fibers. Sodium alginate appears as an irregular particle with sizes ranging from about $100 \mu \mathrm{m}$ to some hundred micrometers. Figure 6 shows the fiber structure of nanofibrillated cellulose with single nanofiber diameters around $\sim 10 \mathrm{~nm}$.

\section{The interaction of components in the composites}

During hydration of hemihydrate, the gypsum crystals appear as needle-like that is interconnected to each other. An addition of biopolymers or other additives modifies the morphology and habit of growing gypsum crystals resulting in the change in microstructures and total porosity of the gypsum composites. It occurs as the presence of biopolymer or other additives changes the supersaturation of the solution and surface topography of the growing gypsum crystals. ${ }^{16}$ During the growth gypsum crystals adopt a variety of habits created by differences in relative growth rates of faces of which the gypsum crystal is composed. Singh and Middendorf $(2007)^{16}$ reported the adsorption on the

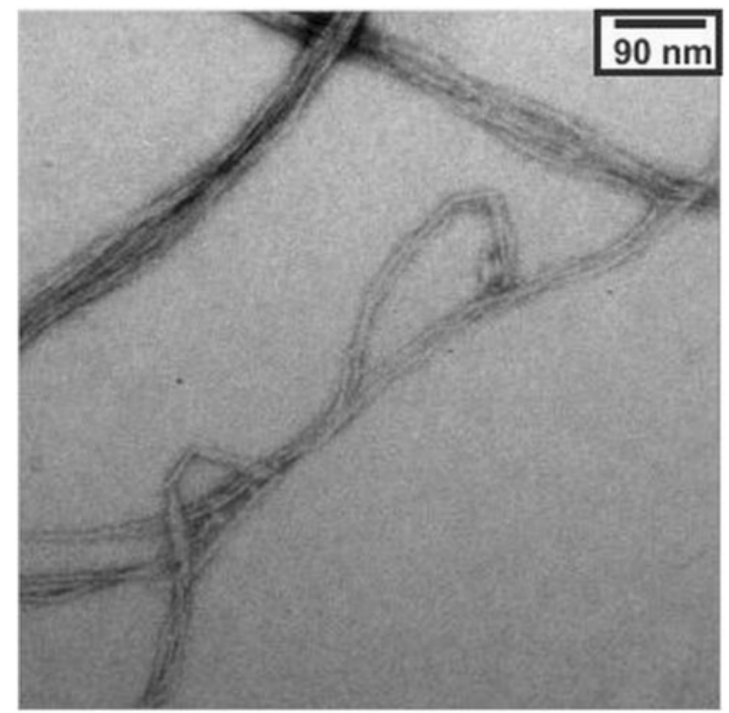

Figure 6. TEM image of fibril aggregates of NFC. Uranylacetate was added to increase the contrast of NFC.

step and kink sites of gypsum crystal faces by retarder agents such as carboxyl groups. It results in the changes of morphology.

The investigated composites were obtained by mixing cellulose ( 1 and $2 \mathrm{wt} \%$ ) and hemihydrate in the presence and absence of sodium alginate. The presence of cellulose independent to the presence of sodium 

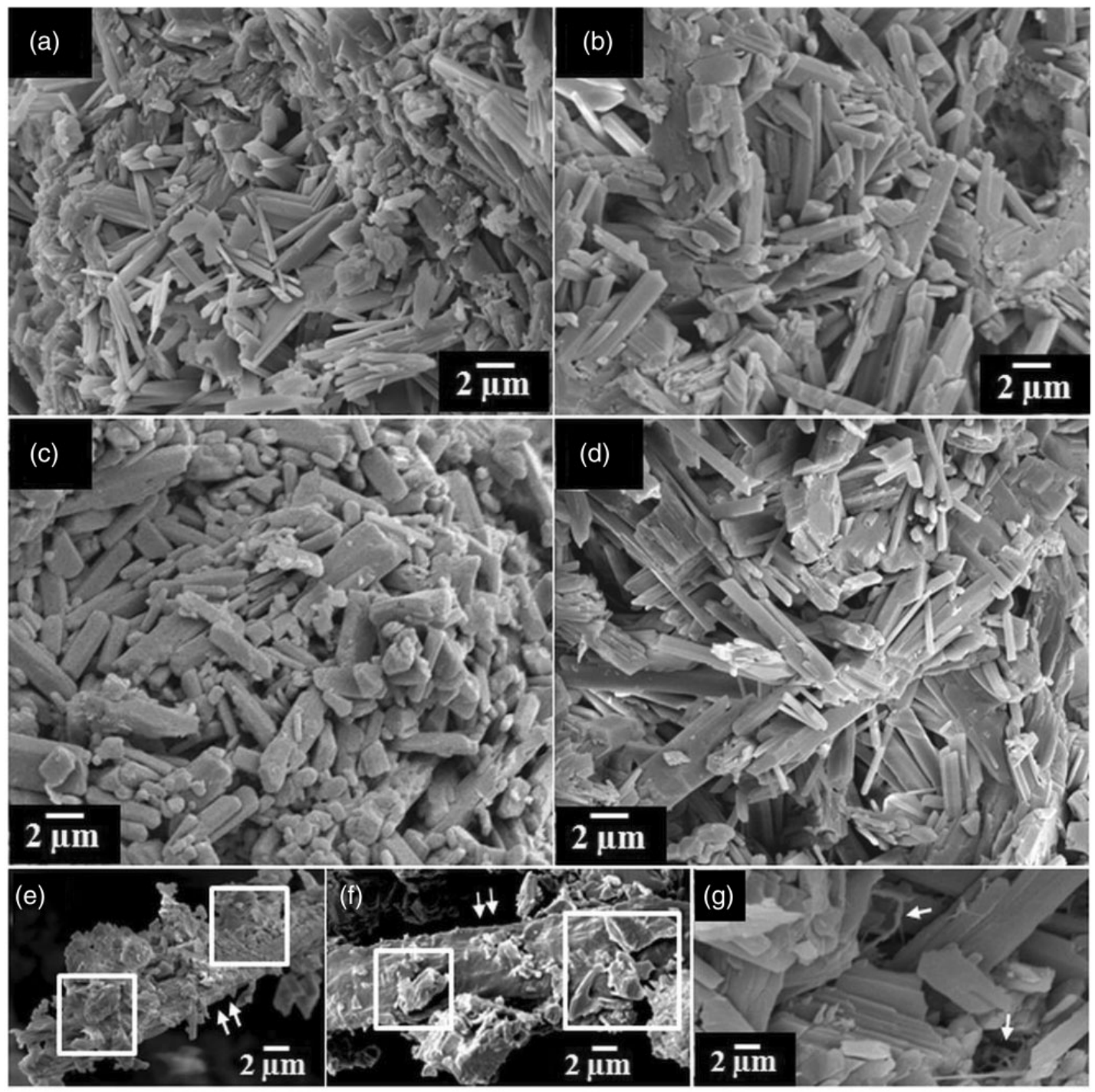

Figure 7. Scanning electron microscopy images of fracture surfaces of the composites. Gypsum crystals in Composite UFC Ia (a) are thinner and smaller than that precipitated in the pure state without any cellulose (Figure 2(c)). Composite B400 2a (b) and Composite Lyo 3a (c) have thick and short gypsum crystals. Composite NFC 4a (d) has gypsum crystal with varied size. Figure (e) shows gypsum crystal grown on the surface of fibrous cellulose B400. Gypsum crystals grown on the surface of Lyocell fiber are shown in figure (f). Figure (g) shows that no gypsum crystals are growing on NFC surface. Double arrows and white squares on figure (e) and (f) indicate the cellulose fiber and gypsum crystals on cellulose fiber surface, respectively. A white single arrow in figure $(\mathrm{g})$ indicates the nanofibrillated cellulose.

alginate changes the gypsum crystal morphology. This change is observed in the different gypsum-gypsum interlocking features (Figure 7). Gypsum crystals of the Composite UFC 1a (Figure 7(a)) are thinner and smaller than those precipitated in the absence of cellulose (Figure 2(b)). The interlocking of gypsum-gypsum crystals of the Composite UFC 1a is disoriented. The addition of B400 (Figure 7(b)) or Lyocell fiber (Figure 7(c)) produces composites with thick gypsum crystals while the addition of NFC (Composite NFC 4a) produces gypsum crystals with varied sizes (Figure 7(d)).

As shown in Figure 7, gypsum nucleation can also occur on the cellulose surface, such as on cellulose B400
(Figure 7(e)) and the Lyocell fiber (Figure 7(f)) surfaces. The nucleation of gypsum on cellulose surfaces (heterogeneous nucleation) impacts the size and morphology of gypsum crystals. On both, B400 and Lyocell fiber, the surficial gypsum crystals tend to form aggregates through the coalescence of individual crystals; marked by white squares in Figure 7(e) and (f). This heterogeneous nucleation is not observed on the surface of nanofibrillated cellulose (Figure $7(\mathrm{~g})$ ). Small fibers, such as in the case of NFC, absorb less water, thus, the amount of water to support gypsum crystallization is less. Cellulose fibers of B400 and Lyocell are marked with double arrows while NFC fiber is marked with single arrows (Figure 7(e) to (g)). 


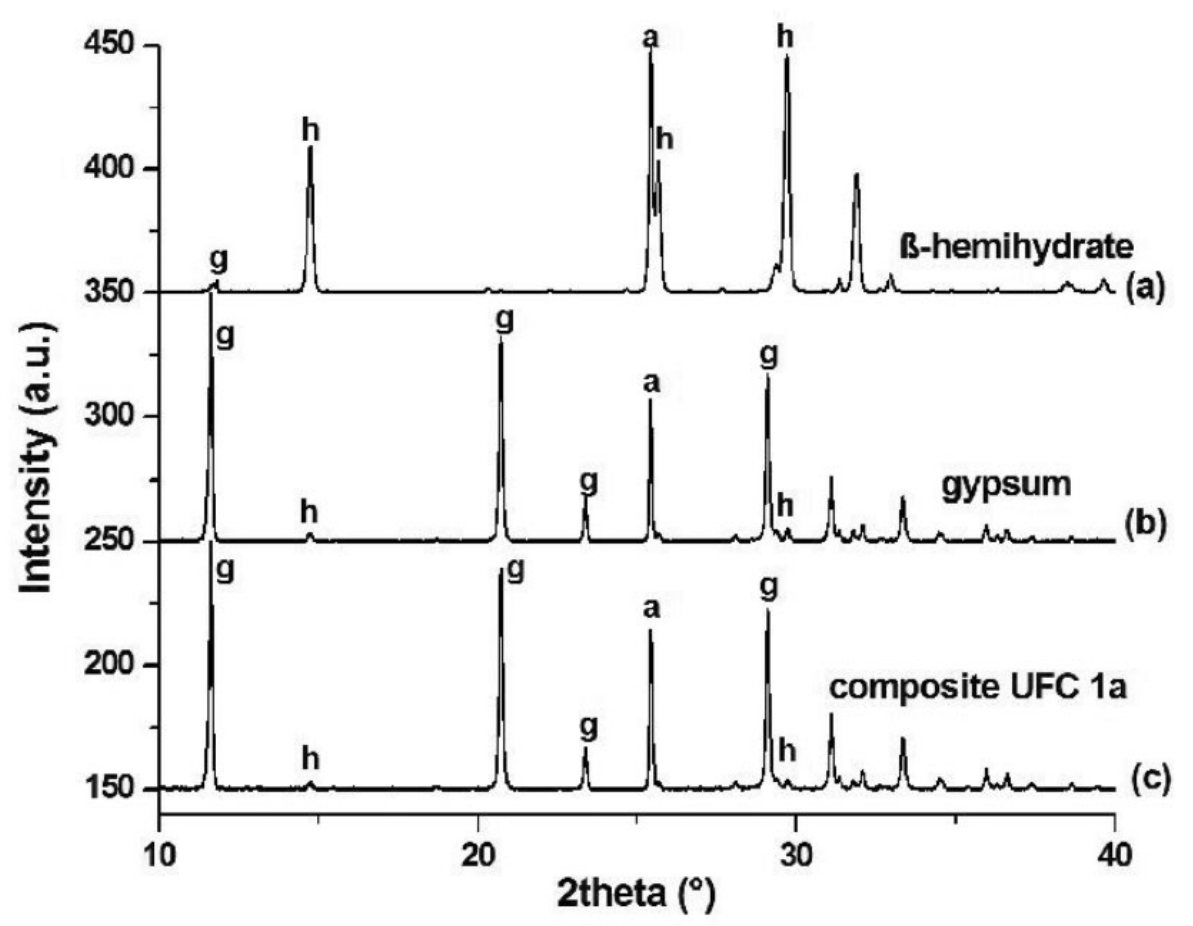

Figure 8. Diffraction patterns of (a) $\beta$-hemihydrate $\left(\mathrm{CaSO}_{4} \cdot \mathrm{l} / 2 \mathrm{H}_{2} \mathrm{O}\right)$, (b) hydrated $\beta$-hemihydrate (gypsum) with a water/hemihydrate $\left(w_{\circ} / h_{\circ}\right)$ ratio of 0.5 , and $(c)$ Composite UFC la with a water/hemihydrate $\left(w_{0} / h_{\circ}\right)$ ratio of 0.5 . Anhydrite is formed and then remains intact. The intensity of hemihydrate peaks decreases and is replaced by the gypsum peaks along the formation of gypsum composites.

Diffraction patterns of $\beta$-hemihydrate (Figure 8(a)), hydrated hemihydrate (gypsum) (Figure 8(b)), and the Composite UFC 1a (Figure 8(c)) are used to follow the transformation of hemihydrate. The hemihydrate peak in the diffraction pattern of the Composite UFC 1a appears at $14.7^{\circ}$ and $29.4^{\circ}(2 \theta)$. The addition of $50 \%$ of water seems to be insufficient to convert all hemihydrate into gypsum. The peak at $29.2^{\circ}(2 \theta)$ is due to gypsum. The anhydrite peak at $25.4^{\circ}(2 \theta)$ is also seen in the diffraction pattern of $\beta$-hemihydrate (an initial ingredient), pure gypsum and the Composite UFC 1a. The appearance of anhydrite in hemihydrate indicates that anhydrite is formed during the hemihydrate production process and is assigned to either anhydrite III or $\gamma-\mathrm{CaSO}_{4}$.

\section{Porosity of the composites}

The total porosity (vol\%) of each composite changes due to the presence of cellulose with or without sodium alginate (Figures 9, 10, 12 and Supplementary $\mathrm{S} 1-\mathrm{S} 3)$. The total porosity of pure gypsum is $47.96 \mathrm{vol} \%$ and increases to $51.31 \mathrm{vol} \%$ when $0.5 \mathrm{wt} \%$ sodium alginate is added. The increase in the total porosity due to sodium alginate addition is a result of a gelation effect of sodium alginate that creates channel-like pores. ${ }^{54,55}$ The composites with cellulose B400 follow a similar total porosity trend to that of composites with Lyocell fibers. The more cellulose is used the higher is the total porosity of the composites. Eve et al. ${ }^{7,8}$ observed the same trend when polyamide fiber was used.

In the case of cellulose UFC100 a different trend was observed. The addition of $1 \mathrm{wt} \%$ cellulose UFC100 decreases the total porosity of the composite. Cellulose UFC100 has small particles with sizes less than $10 \mu \mathrm{m}$. These particles can fill the voids that occur from the entanglements of gypsum crystals. The addition of $0.5 \mathrm{wt} \%$ sodium alginate indisputably increases the total porosity of the composite. The composite with $2 \mathrm{wt} \%$ cellulose UFC 100 has an increase in total porosity as a result of the increasing amount of cellulose UFC100. The total porosity decreases when $0.5 \mathrm{wt} \%$ sodium alginate is added having a similar total porosity value to that of the composite with $1 \mathrm{wt} \%$ cellulose and $0.5 \mathrm{wt} \%$ sodium alginate. This suggests that cellulose UFC100 only partly fills the channel-like pores created by sodium alginate.

The composite with $1 \mathrm{wt} \%$ of NFC has a similar total porosity value to that of the pure gypsum. The total porosity does not change when $0.5 \mathrm{wt} \%$ sodium alginate is added. It proves that NFC fills the channellike pores created by sodium alginate. Composites with $2 \mathrm{wt} \%$ NFC have a high water/hemihydrates ratio resulting to a high total porosity. High water/hemihydrates ratio clearly influences the total porosity as seen in Figure S1. 

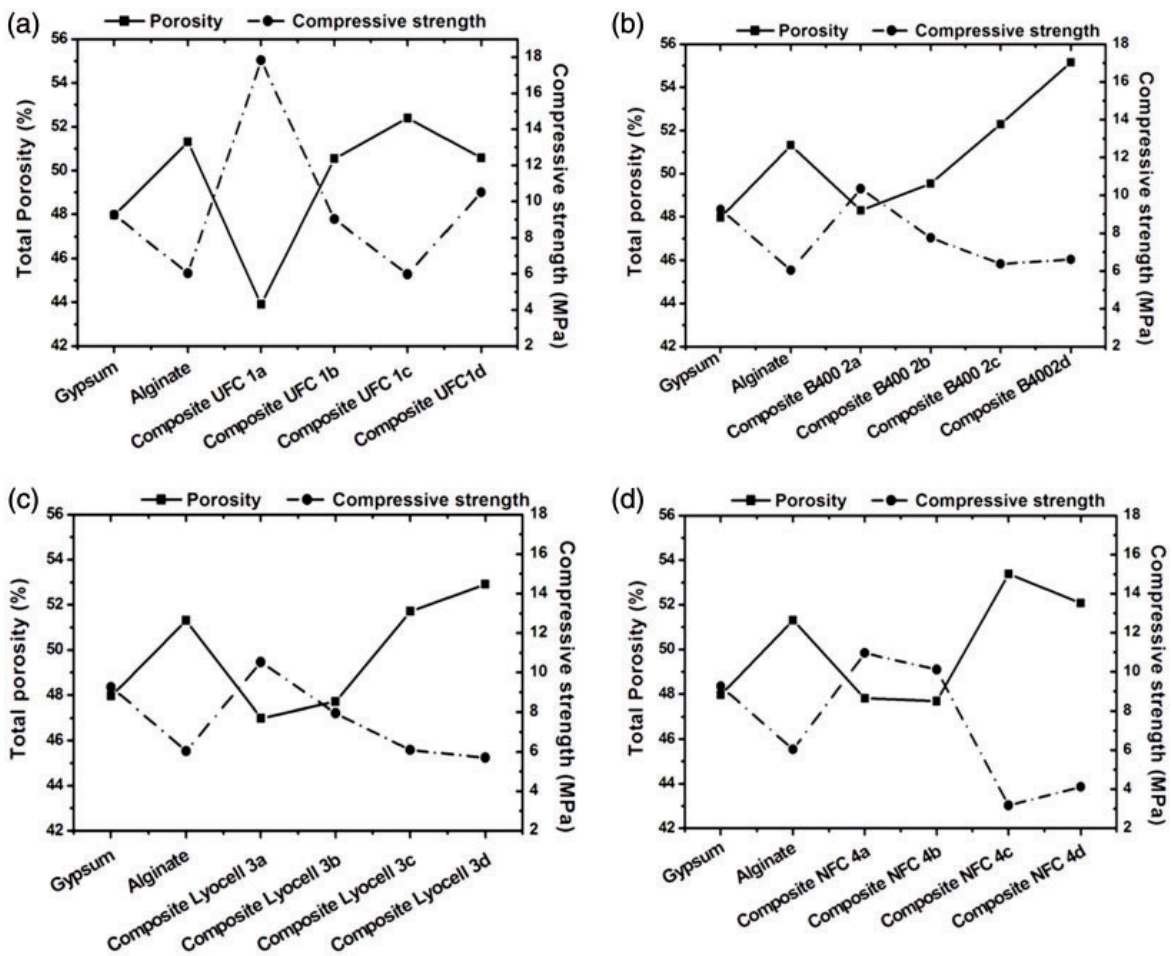

(e)

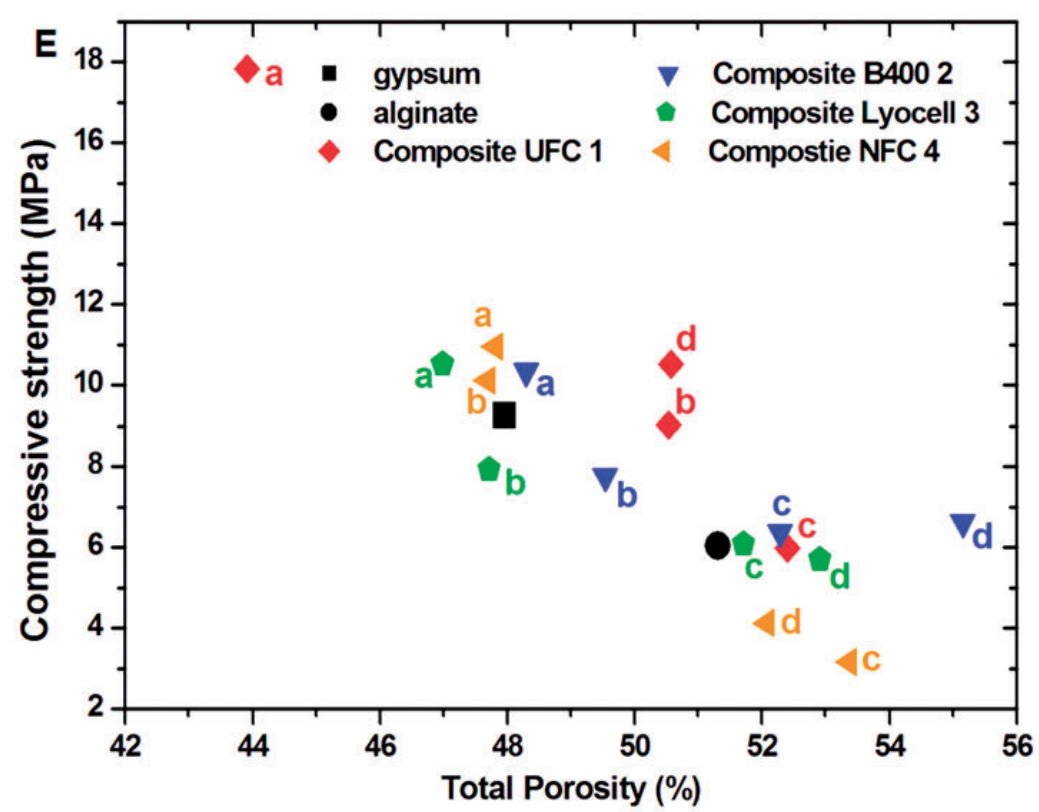

(a) addition of $1 \mathrm{wt} \%$ cellulose

(b) addition of $1 \mathrm{wt} \%$ cellulose and $0.5 \mathrm{wt} \%$ sodium alginate (c) addition of 2 wt \% cellulose

(d) addition of $1 \mathrm{wt} \%$ cellulose and $0.5 \mathrm{wt} \%$ sodium alginate

Figure 9. The graphs of the total porosity and the compressive strength of the cellulose/gypsum composites as a function of the composites: (A) composites UFCI00, (B) composites B400, (C) composites Lyocell and (D) composites NFC. The graphs show that the total porosity influences the compressive strength of the final composites. Figure (E) shows the total porosity of the cellulose/ gypsum (UFC100, B400, Lyocell and NFC) for different cellulose/gypsum mixtures given as a, b, c and d as a function of compressive strength. The pure gypsum reference with $w_{0} / h_{0}$ of 0.97 is shown in Figure $\mathrm{SI}$.

\section{Mechanical properties of the composites}

The compressive and bending (flexural) strength values as well as the total porosity are presented as a function of the composites (Figures 9 and 10). The graphs of the total porosity of the composites as a function of the compressive and bending (flexural) strength are also shown (Figures 9 and 10). Box the compressive and bending 

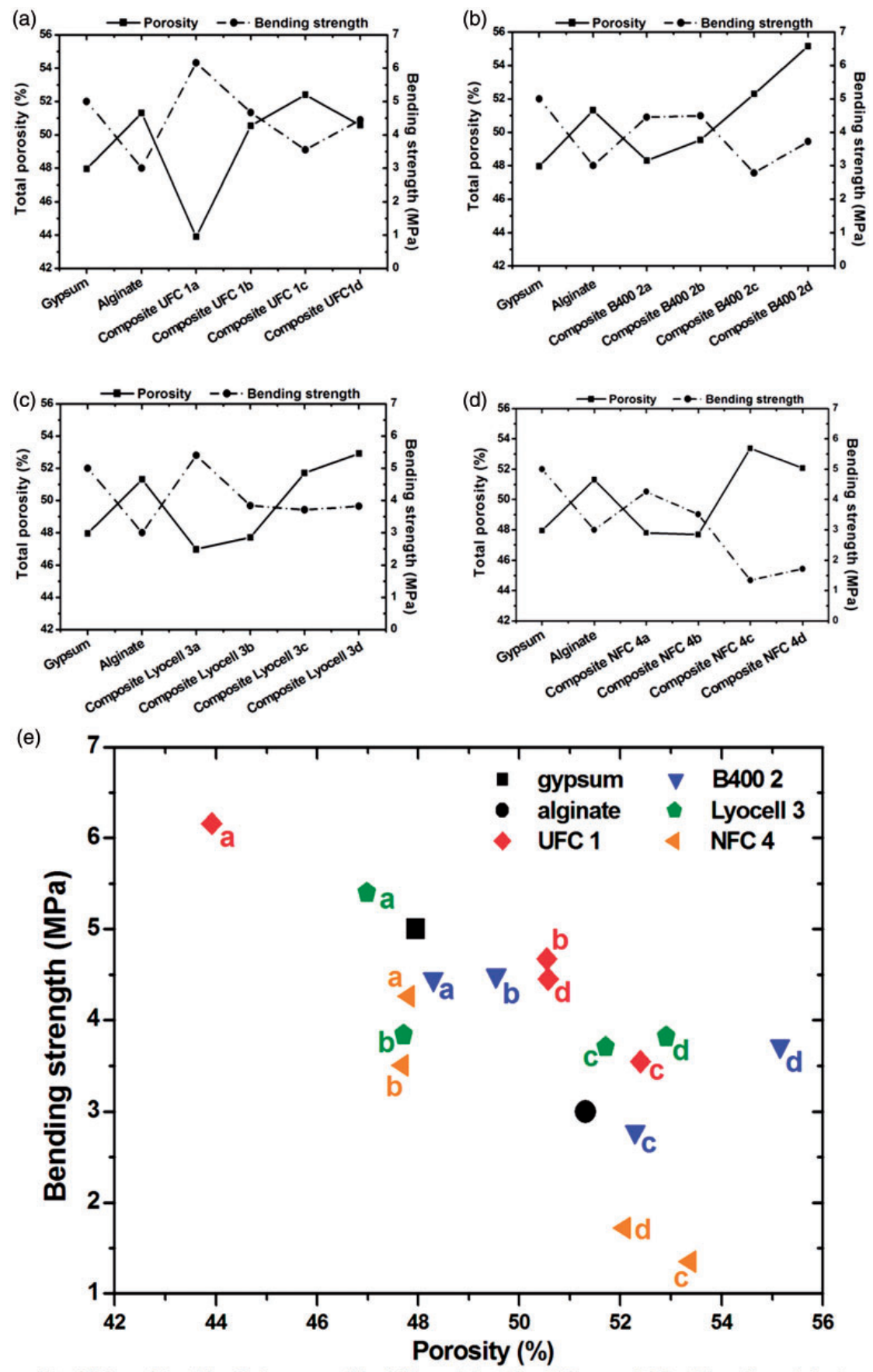

(a) addition of $1 \mathrm{wt} \%$ cellulose

(b) addition of $1 \mathrm{wt} \%$ cellulose and $0.5 \mathrm{wt} \%$ sodium alginate (c) addition of $2 \mathrm{wt} \%$ cellulose

(d) addition of $1 \mathrm{wt} \%$ cellulose and $0.5 \mathrm{wt} \%$ sodium alginate

Figure 10. The graphs of the total porosity and the bending strength of the cellulose/gypsum composites as a function of the composites: (A) composites UFC100, (B) composites B400, (C) composites Lyocell, (D) composites NFC and (E) shows the total porosity of the all cellulose/gypsum composites for different cellulose/gypsum mixtures given as a, b, $\mathrm{c}$, and $\mathrm{d}$ as a function of bending strength. The graphs show that the total porosity influences the bending strength of the final composites. The bending strength of the composites follows the same trend like the other mechanical property of the composites such as the compressive strength.

strength show maximum and minimum bars along with the median, the lower quartile $\left(75^{\text {th }}\right.$ percentile), and the lower percentile $\left(25^{\text {th }}\right.$ percentile) (Figure S2). The reference, the pure gypsum, has a compressive strength of
$9.25 \pm 1.25 \mathrm{MPa}$ and a bending strength of $5.65 \pm 1.15 \mathrm{MPa}$ (mean \pm standard deviation) (Table 1 ). The content of cellulose added to the composite is 1 and $2 \mathrm{wt} \%$ and that of sodium alginate is $0.5 \mathrm{wt} \%$. Regarding 

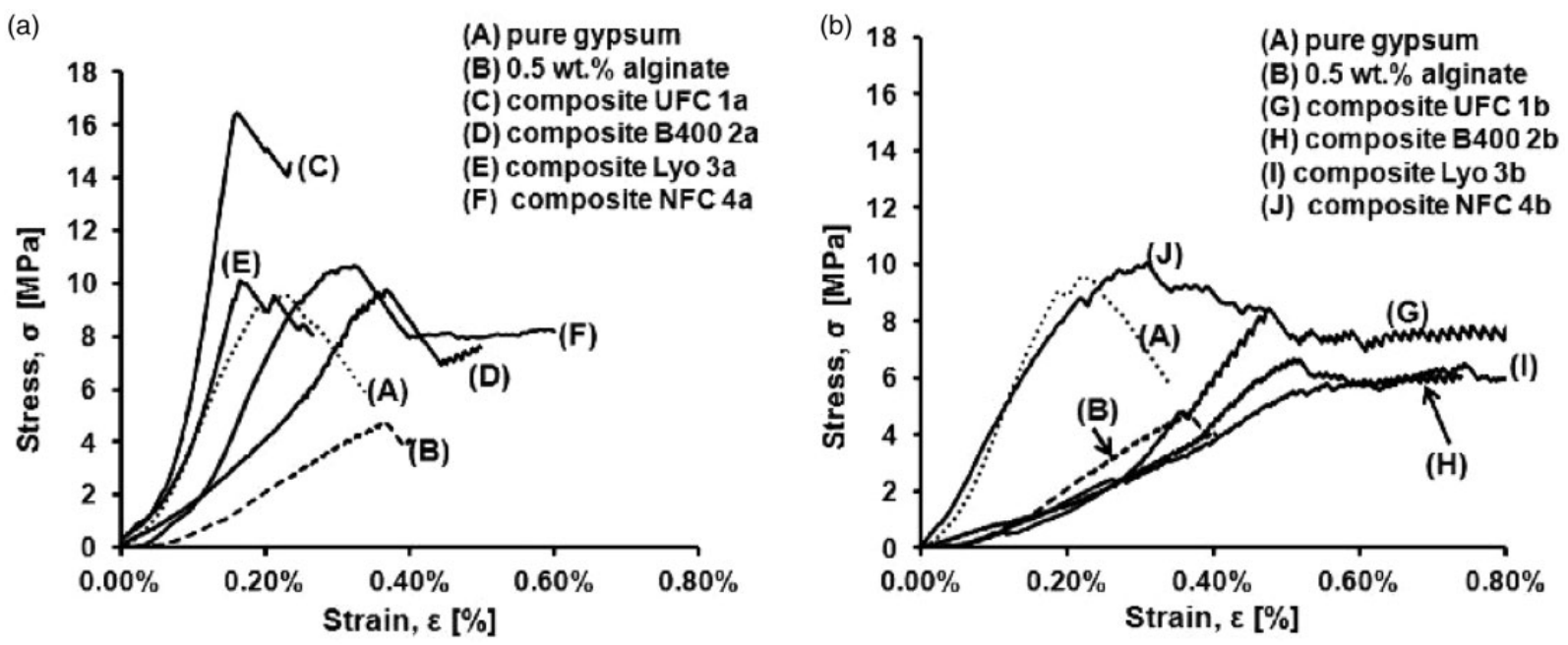

Figure II. Stress-strain curves of (a) composites with I wt\% of cellulose without sodium alginate and (b) composites with I wt\% cellulose and $0.5 \mathrm{wt} \%$ sodium alginate. The stress-strain curves of pure gypsum in the presence and absence of sodium alginate are included as references.

their compressive and bending strength values, all composites differ from each other. The addition of $1 \mathrm{wt} \%$ cellulose UFC100 (Composite UFC 1a) increases the compressive strength of the composite up to $17.82 \pm 1.07 \mathrm{MPa}$, almost twice the compressive strength of the pure gypsum reference. The compressive strength then decreases as $0.5 \mathrm{wt} \%$ sodium alginate is added (Composite UFC 1b), giving a compressive strength value similar to that of pure gypsum. The decrease of the compressive strength continues as $2 \mathrm{wt} \%$ cellulose UFC100 is added (Composite UFC 1c). Finally, the compressive strength value increases, slightly to a value higher than that of the pure gypsum, when $0.5 \mathrm{wt} \%$ sodium alginate is added to the composite of $2 \mathrm{wt} \%$ cellulose UFC100 (Composite UFC 1d). Composites with cellulose B400 and Lyocell fiber show the similar trends. Composites with cellulose B400 (Composite B400 2) or Lyocell fiber (Composite Lyo 3) have the same decreasing trend as more cellulose B400 or Lyocell fiber is added, independent to the presence of sodium alginate. Composites NFC $4 \mathrm{c}$ and $4 \mathrm{~d}$ have low compressive strength values due to the high porosity of the composite material as a result of the high amount of water (Figure $\mathrm{S} 1)$. The addition of $1 \mathrm{wt} \% \mathrm{NFC}$, independent of the addition of sodium alginate (Composite NFC 4a and $4 b$ ), gave a slight increase in compressive strength in comparison to that of the pure gypsum reference. The bending strength (Figure 10) follows a similar trend to that of the compressive strength.

Figure 11 shows stress-strain curves of the cellulose/ gypsum composites tested in compression. As seen in Figure 11(a) the slope of the stress-strain curve of the Composite UFC 1a (C), up to an ultimate strain value of $0.2 \%$, is more steep in comparison to that of the other composites. The Composites B400 2a (D), Lyo 3a (E), and NFC 4a (F) have a compressive strength that is similar to that of pure gypsum (A) with the ultimate strain values of $0.38 \%, 0.18 \%$, and $0.25 \%$, respectively. The composites with $1 \mathrm{wt} \%$ cellulose in the presence of $0.5 \mathrm{wt} \%$ sodium alginate such as Composite UFC100 1b (G), Composite B400 2b (H) and Composite Lyo 3b (I) have an almost constant load after the first load drop is observed. These composites have ultimate strain values that are in the range of $0.4-0.8 \%$ and are even higher than that of the sodium alginate (B). The addition of $0.5 \mathrm{wt} \%$ sodium alginate to $1 \mathrm{wt} \%$ NFC, Composite NFC $4 \mathrm{~b}(\mathrm{~J})$, does not give a big difference in the ultimate value in comparison to that of the Composite NFC 4a (F), composite without sodium alginate.

The Young's moduli of investigated samples and the total porosity are presented as a function of the composites (Figure 12). The box plot of Young's modulus shows maximum and minimum bars along with the median, the lower quartile $\left(75^{\text {th }}\right.$ percentile), and the lower percentile $\left(25^{\text {th }}\right.$ percentile) (Figure S3). The Young's modulus of pure gypsum in the absence and presence of $0.5 \mathrm{wt} \%$ sodium alginate are shown as references. Composites with $1 \mathrm{wt} \%$ cellulose UFC or Lyocell fiber have significantly high Young's modulus values, almost as high as that of the pure gypsum reference. A slight increase of Young's moduli is observed when $1 \mathrm{wt} \%$ cellulose B400 or NFC is added. The Young's moduli of all composites drop when $0.5 \mathrm{wt} \%$ sodium alginate is added to the composites. Composite NFC $4 \mathrm{~b}$ shows a slight increase of Young's modulus when $0.5 \mathrm{wt} \%$ sodium alginate is added. Note the big scatter of the data shown in the box plot (Figure S3). 

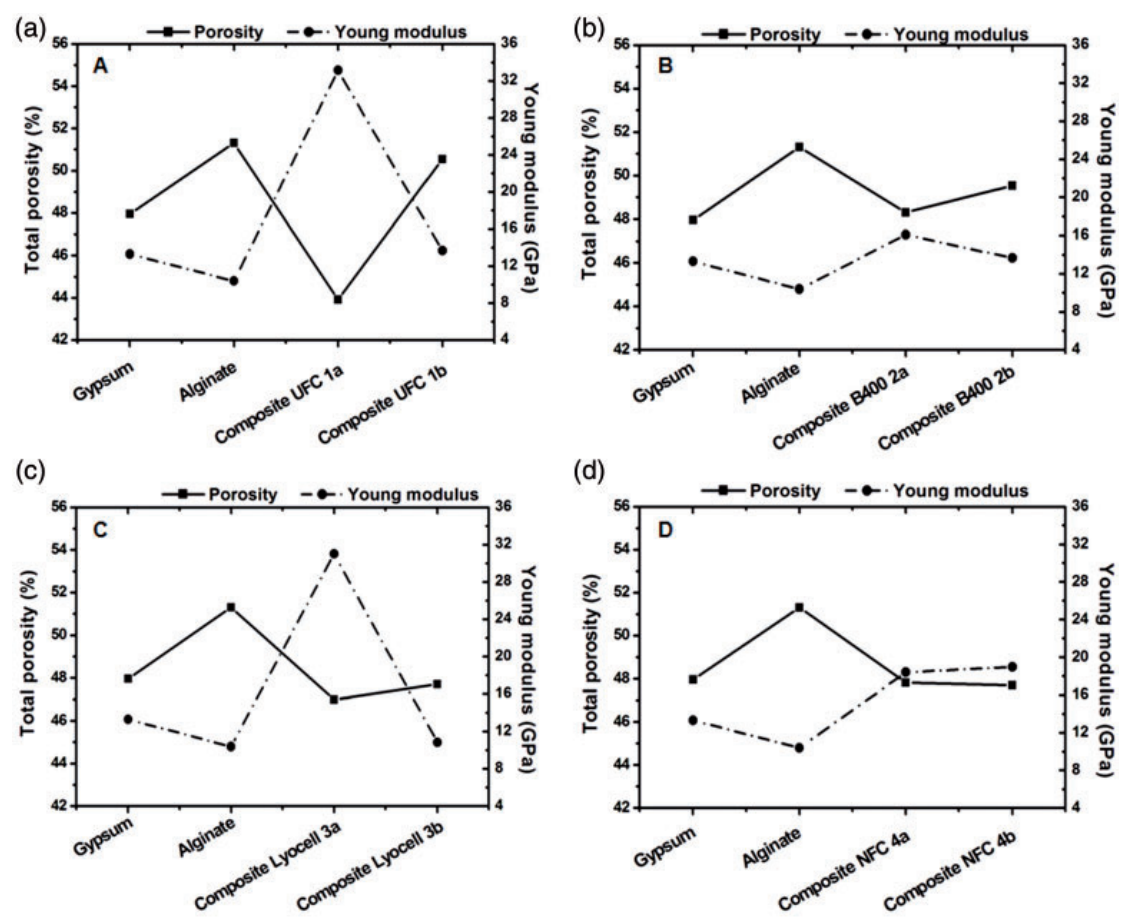

(e)

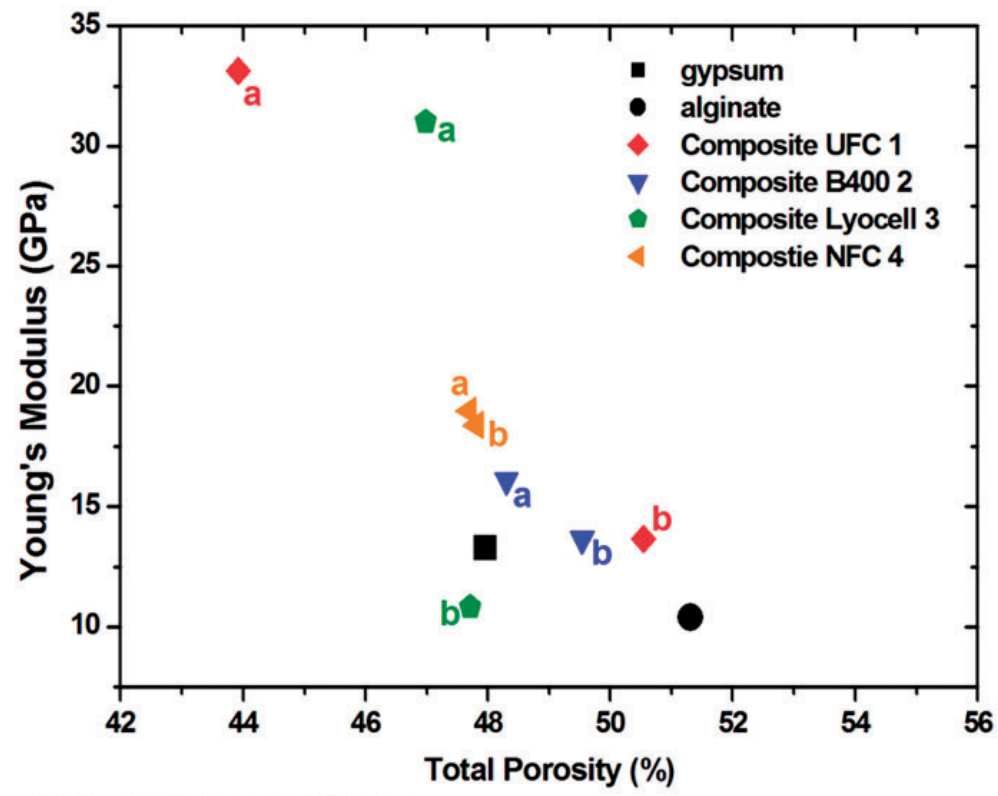

(a) An addition of 1 wt \% cellulose

(b) An addition of $1 \mathrm{wt} \%$ cellulose and $0.5 \mathrm{wt} \%$ alginate

Figure 12. The graphs of the total porosity and the Young's modulus of the cellulose/gypsum composites as a function of the composites: (A) composites UFC100, (B) composites B400, (C) composites Lyocell, and (D) composites NFC. Graph (E) show the total porosity of all composites as a function of Young's modulus. The graphs show that the total porosity influences the Young's modulus of the final composites. Composite with an addition of I wt\% cellulose UFCI00 (UFC I a) has the highest Young's modulus as an effect of low total porosity. 


\section{Discussion}

\section{The role of cellulose in the gypsum crystallization}

Polyamide, hemp, and cellulose fibers are commonly used to reinforce gypsum composites and are well-known to affect the properties of the composite materials. However, the role of cellulose during gypsum crystal formation, growth, and gypsum-gypsum crystal interlocking has not yet been clearly explained. In this contribution we try to point out this issue. In several composites heterogeneous gypsum nucleation occurs on the surface of cellulose. Such heterogeneous nucleation might be favored by a good matching interface between the structures of gypsum and the different characteristics of the celluloses materials such as the ability of cellulose to absorb and provide water for gypsum crystallization. When gypsum nucleates heterogeneously on cellulose such as in the case of cellulose B400 and Lyocell fiber (Figure 7(e) and (f)), the crystal morphology as well as the interlocking features strongly differ from the case in the pure gypsum precipitates. Heterogeneous nucleation does not appear on the surface of NFC. With a decreasing size of the fiber less water is absorbed by the fiber. Thus, a smaller quantity of water will be released to support gypsum crystallization.

As seen in the SEM image of the composite where UFC100 1a is added (Figure 7(a)), cellulose UFC100 produces smaller gypsum crystals in comparison to gypsum crystals precipitated without any cellulose. The addition of UFC100 reduces the porosity of the gypsum composite, thus enhances the bending and compression strength of the Composite UFC 1a (Figures 9, 10, S2, and S3).

\section{The effect of cellulose characteristics and sodium alginate on the mechanical properties of the composites}

Cellulose is a complex organic material with unique properties. In this study, two distinct cellulose polymorphs were used: Cellulose I (cellulose UFC100, cellulose B400, and NFC) (Figure 3) and cellulose II (Lyocell fiber) (Figure 4). Cellulose UFC100, B400, and NFC are natural fibers, while Lyocell is a synthetic fiber. Cellulose I shows a high degree of crystallinity (degree of crystallinity values of $75.5 \%, 70.2 \%$, and $67.8 \%$ for UFC100, B400, and NFC, respectively) whereas cellulose II is more amorphous in comparison to cellulose I (degree of crystallinity value of $52.3 \%$ ) (Table 2). The degree of crystallinity is correlated to the arrangement of individual fibrils within a cellulose fiber. The degree of crystallinity further defines the degree of swelling and the water retention value (WRV) of the cellulose. The degree of swelling in water or $\mathrm{NaOH}(2-4 \mathrm{M})$ is higher for cellulose II in comparison to that of cellulose I. Under strong alkali treatment $(\mathrm{NaOH}$ of 5-8 M), cellulose I has a higher degree of swelling than that of cellulose II. ${ }^{33}$ The small swelling degree of cellulose I in water and under alkali treatment $(\mathrm{NaOH}$ of $2-4 \mathrm{M})$ is due to the fact that cellulose I has a high degree of crystallinity and contain less disordered interlayers between the crystallites of the elementary fibrils. ${ }^{38}$ This results in a lower uptake of water by cellulose I in comparison to cellulose II.

The degree of swelling together with the WRV influence the total porosity. ${ }^{33}$ The total porosity further influences the mechanical properties of the composite (compressive strength, bending strength, and Young's modulus) (Figures 9, 10, and 12). Note the scatter of data in the box plots (Figures S2 and S3). The significant increase in Young's modulus of the composite with UFC100 is due to a fact that cellulose UFC100 is an ultrafine cellulose powder that can penetrate the pores created by the gypsum needle-like matrix. This reduces the total porosity of the composite. The high Young's modulus of the composite with $1 \mathrm{wt} \%$ Lyocell proofs that Lyocell fiber (synthetic fiber) has a high stiffness. The composite with $1 \mathrm{wt} \%$ NFC has a Young's modulus value higher than that of composite with $1 \mathrm{wt} \% \mathrm{~B} 400$. NFC is reported by some authors $^{39-42}$ as having a high stiffness.

Cellulose and sodium alginate act as biopolymers that influence the mechanical properties of cellulose/gypsum composites. The composites consist of the gypsum matrix enforced by cellulose fibers and sodium alginate. The gypsum matrix infiltrates the cellulose fibers and affects the mechanical property of the composites depending on the fiber characteristics. The presence of sodium alginate increases the total porosity of the composites by creating more pores (Figures 9 and 10). Cellulose UFC 100, the cellulose with small particles, is able to impregnate the pores created by gypsum-gypsum interlocking, thus, decrease the total porosity of the composite (Composite UFC 1a). The decrease in total porosity correlates with an increase in the mechanical properties of the Composite UFC 1a (Figures 9 and 10). The stress-strain curve behavior that is observed after the first load drop appears as a result of an intimate interlinkage between cellulose and sodium alginate so that an effective load transfer between the matrix and the fibers is achieved. This behavior is not observed when cellulose alone is added to gypsum (Figure 11). The addition of sodium alginate to the cellulose/gypsum composite with NFC does not affect the Young's modulus of the composites (Composites NFC $4 a$ and $4 b$ ). This clearly explains that sodium alginate does not reduce the NFC-gypsum interface failure by creating an intimate interlinkage between NFC and gypsum interfaces.

\section{Conclusions}

We investigated the total porosity and mechanical properties of cellulose/gypsum composites in the 
presence and absence of sodium alginate. Our results show that the morphology of cellulose not only affects the formation of gypsum crystals but also the microstructure and the mode of the interlocking of the gypsum crystals. It occurs as the presence of cellulose changes the supersaturation of the solution and surface topography of the growing crystals. A heterogeneous nucleation that is observed in the surface of the cellulose is affected by a good matching interface between the structures of gypsum and the different characteristics of the celluloses materials such as the ability of cellulose to absorb and provide water for gypsum crystallization.

The gypsum microstructure and mode of interlocking further influence the total porosity and the mechanical properties of the final composite material. The compressive strength, bending strength and Young's modulus increase with the addition of cellulose UFC100 due to the fact that UFC100 is a cut off fiber with an irregularly shaped unit and is able to fill the pores of the composites. A high stiffness of Lyocell fiber, a synthetic fiber, resulted in a high Young's modulus of the composite with the addition of $1 \mathrm{wt} \%$ Lyocell fiber. The addition of sodium alginate reduces the interface failure as it is seen in stressstrain curves showing a high ultimate strain value.

\section{Acknowledgments}

We thank Markus Sieber and the staffs of the workshop of Department of Earth and Environmental Sciences, Ludwig Maximilian University for technical support. We also thank Dr Robin Beddoe from Centre of Building Material, Technische Universität Muenchen for his help with the porosity measurement.

\section{Conflict of interest}

None declared.

\section{Funding}

This work was partially funded by projects AIB2010 DE00085, DAAD-50749739 and KAAD.

\section{References}

1. Wirsching F. Calcium sulfate. In: Pfefferkorn $\mathrm{R}$ and Rounsaville JF (eds) Ullmann's encyclopedia of industrial chemistry. Fifth, completely revised edition. Weinheim: VCH Verlagsgesellschaft GmbH, 1985, pp.555-584.

2. Gmouh A, Samdi A, Moussa R, et al. Lightened plasterbased composite materials:Elaboration and mechanical properties. Silicat Indust Ceram Sci Technol 2001; 66: 61-66.

3. Coutts R. Wastepaper fibers in plaster products. J Mater Sci Lett 1991; 10: 77-78.

4. Olvares-Hernández F, Oteiza I and de Villanueva L. Experimental analysis of toughness and modulus of rupture increase of sisal short fiber reinforced hemihydrate gypsum. Compos Struct 1992; 22: 123-137.
5. Li G, Yu Y, Zhao Z, et al. Properties study of cotton stalk fiber/gypsum composite. Cement Concrete Res 2003; 33: 43-46.

6. Dalmay P, Smith A, Chotard T, et al. Properties of cellulosic fiber reinforced plaster: Influence of hemp or flax fiber on the properties of set gypsum. J Mater Sci 2010; 45: 793-803.

7. Eve S, Gomina M, Gmouh A, et al. Microstructural and mechanical behavior of polyamide fiber-reinforced plaster composites. J Eur Ceram Soc 2002; 22: 2269-2275.

8. Eve S, Gomina M, Pernot JP, et al. Microstructure characterization of polyamide fiber/latex-filled plaster composites. J Eur Ceram Soc 2007; 27: 3517-3525.

9. Ali MA and Grimer FJ. Mechanical properties of glass fiber-reinforced gypsum. J Mater Sci 1969; 4: 389-395.

10. Wu YF and Dare MP. Axial and shear behavior of glass fiber reinforced gypsum wall panels. J Compos Constr 2004; 8: 569-578.

11. Wu YF. The effect of longitudinal reinforcement on the cyclic shear behavior of glass fiber reinforced gypsum wall panels. Eng Struct 2004; 11: 1663-1646.

12. El-Maghraby HF, Gedeon $\mathrm{O}$ and Khalil AAA. Formation and characterization of poly(vinyl alcoholco-vinyl-acetate-itaconic acid)/plaster composites, part 2. Composite formation and characterization. Ceramics 2007; 3: 168-172.

13. Chen Z, Sucech S and Faber KT. A hierarchical study of the mechanical properties of gypsum. J Mater Sci 2010; 45: 4444-4453.

14. Lewry AJ and Williamson J. The setting of gypsum plaster, part I: The hydration of calcium sulphate hemihydrates. J Mater Sci 1994; 29: 5279-5284.

15. Badens E, Veesler S and Boistelle R. Crystallization of gypsum from hemihydrate in presence of additives. J Crys Growth 1999; 198: 704-709.

16. Singh NB and Middendorf B. Calcium sulphate hemihydrates hydration leading to gypsum crystallization. Prog Cryst Growth Ch 2007; 53: 57-77.

17. Yu QL and Brouwers HJH. Microstructure and mechanical properties of $\beta$-hemihydrate produced gypsum: An insight from its hydration process. Constr Build Mater 2011; 25: 3149-3157.

18. Padevět $\mathrm{P}$, Tesárek $\mathrm{P}$ and Plachý T. Evolution of mechanical properties of gypsum in time. Int $J$ Mech 2011; 5: $1-9$.

19. Singh NB, Vellmer C and Middendorf B. Effect of carboxylic acids on the morphology, physical characteristics and hydration of $\alpha$-hemihydrate plaster. Indian $J$ Eng Mater Sci 2005; 12: 337-344.

20. Amathieu L and Boistelle R. Improvement of the mechanical properties of set plasters by means of four organic additives inducing $\{101\}$ faces. J Cryst Growth 1986; 79 : 169.

21. Osterwalder N, Loher S, Grass RN, et al. Preparation of nano-gypsum from anhydrite nanoparticles. J Nanopart Res 2007; 9: 275.

22. Singh $M$ and Garg M. Gypsum-based fibre-reinforcement composites: An alternative to timber. Constr Build Mater 1994; 8: 155-160. 
23. Bastidas JC, Pawlak JJ, Venditti RA, et al. A colloidal probe microscopy study of cellulose/gypsum interactions. Mater Charact 2008; 59: 144-150.

24. Rusli R and Eichhorn J. Determination of the stiffness of cellulose nanowhiskers and the fiber-matrix interface in a composite using Raman spectroscopy. Appl Phys Lett 2008; 93: 033111.

25. Li Q and Renneckar S. Supramolecular structure characterization of molecularly thin cellulose I nanoparticles. Biomacromolecules 2011; 12: 650-659.

26. Tanpichai S, Quero F, Nogi M, et al. Effective Young's modulus of bacterial and microfibrillated cellulose fibrils in fibrous networks. Biomacromolecules 2012; 13: 1340-1349.

27. O'Sullivan AC. Cellulose: The structure slowly unravels. Cellulose 1997; 4: 173-207.

28. Finkenstadt VL and Millane RP. Crystal structure of Valonia Cellulose Iß. Macromolecules 1998; 31: 7776-7783.

29. Wada M, Nishiyama Y and Langan P. X-ray structure of ammonia-cellulose I: New insights into the conversion of cellulose I to cellulose IIII. Macromolecules 2006; 39: 2947-2952.

30. Wada M, Nishiyama Y, Chanzy H, et al. Lyocell: The new generation of regenerated cellulose. JCPDSInternational Centre for Diffraction Data, 2008, pp. 138-144.

31. Langan P, Nishiyama $Y$ and Chanzy H. X-ray structure of mercerized cellulose II at $1 \AA$ resolution. Biomacromolecules 2012; 2: 410-416.

32. de Maria Pinheiro Correia $C$ and de Souza MF. Mechanical strength and thermal conductivity of lowporosity gypsum plates. Mater Res 2009; 12: 95-99.

33. Paul UC, Manian AP, Śiroká B, et al. Sorption of anionic polysaccharide by cellulose. Carbohydr Polym 2012; 87: 695-700.

34. Özturk HB, Potthast A, Rosenau T, et al. Changes in the intra- and inter-fibrillar structure of Lyocell (TENCEL ${ }^{\circledR}$ ) fibers caused by $\mathrm{NaOH}$ treatment. Cellulose 2009; 16 : 37-52.

35. Ehrhardt A, Groner S and Bechtold T. Swelling behavior of cellulosic fibers - Part I: Changes in physical properties. Fibre Text East Eur 2007; 15: 46-48.

36. Oztürk $\mathrm{HB}$ and Bechtold T. Effect of $\mathrm{NaOH}$ treatment on the interfibrillar swelling and dyeing properties of Lyocell (TENCEL ${ }^{\circledR}$ ) fibres. Fibre Text East Eur 2007; 15: 114-117.

37. Lenz J, Schutz J and Wrentschur E. Properties and structure of solvent-spun and viscose-type fibres in the swollen state. Colloid Polym Sci 1993; 271: 460-468.

38. Zimmermann T, Bordeanu N and Strub E. Properties of nanofibrillated cellulose from different raw materials and its reinforcement potential. Carbohydr Polym 2010; 79: 1086-1093.

39. Zadorecki P and Michell AJ. Future-prospects for wood cellulose as reinforcement in organic polymer composites. Polym Compos 1989; 10: 69-77.

40. Yano H and Nakahara S. Bio-composites produced from plant microfiber bundles with a nanometer unit web-like network. J Mater Sci 2004; 39: 1635-1638.
41. Hubbe MA, Rojas OJ, Lucia LA, et al. Cellulosic nanocomposites: A review. Bio Res 2008; 3: 929-980.

42. Eyholzer C, Lopez-Suevos F, Tingaut $P$, et al. Reinforcing effect of carboxymethylated nanofibrillated cellulose powder on hydroxypropyl cellulose. Cellulose 2010; 17: 793-802.

43. Marín-Galán C, Rivera-Gómez C and Petric J. Claybased composite stabilized with natural polymer and fibre. Constr Build Mater 2010; 24: 1462-1468.

44. Hay ID, Rehman ZU and Rehm BH. Membrane topology of outer membrane protein Algae which is required for alginate production in pseudomonas aeruginosa: Identification of two aflatrem biosynthesis gene loci in Aspergillus flavus and metabolic engineering of Penicillium paxilli to elucidate their function. Am Soc Microbiol 2010; 76: 1806-1812.

45. Andresen IL, Skipnes O, Smidsrod O, et al. Some biological functions of matrix components in benthic algae in relation to their chemistry and the composition of seawater. ACS Symp Ser 1977; 48: 361-381.

46. Friedemann K, Stallmach F and Kärger F. NMR diffusion and relaxation studies during cement hydration. Cem Concr Res 2006; 36: 817-826.

47. Rivier-Gómez C, Galán-Marín C and Bradley F. Analysis of the influence of the fiber type in polymer matrix/fiber bond using natural organic polymer stabilizer. Polymers 2014; 6: 977-994.

48. Teeäär R, Serimaa R and Paakkari T. Crystallinity of cellulose, as determined by CP/MAS NMR and XRD methods. Polym Bull 1987; 17: 231-237.

49. Terinte N, Ibbett R and Schuster KC. Overview on native cellulose and microcrystalline cellulose I structure studied by X-ray diffraction (WAXD): Comparison between measurement techniques. Lenzinger Berichte 2010; 89: 118-131.

50. Park S, Baker JO, Himmel ME, et al. Cellulose crystallinity index: Measurement techniques and their impact on interpreting cellulose performance. Biotechnol Biofuels 2010; 3: 1-10.

51. Focher B, Palma MT, Canetti M, et al. Structural differences between non-wood plant cellulloses: evidence from solid state NMR, vibrational spectroscopy and X-ray diffractomer. Ind Corp Prod 2001; 13: 193-208.

52. Kaushik A and Singh M. Isolation and characterization of cellulose nanofibril from wheat straw using steam explosion coupled with high shear homogenization. Carbohydr Res 2011; 346: 76-85.

53. Cardew PT and Davey RJ. The kinetics of solventmediated phase transformations. Proc R Soc Lond 1985; 398: 415-428.

54. Thumbs $\mathrm{H}$ and Kohler HH. Capillaries in alginate gels as an example of dissipative structure formation. Chem Phys 1996; 208: 9-24.

55. d'Ayala GC, Malinconico M and Laurienzo P. Marine derived polysaccharide for biomedical applications: Chemical modification approaches. Molecules 2008; 13 : 2069-2106. 